\title{
Os conceitos de formação e semiformação de Adorno na análise de trabalhos de conclusão de curso sobre questões sociocientíficas na graduação em Pedagogia
}

\author{
Adorno's concepts of education and half-education in the \\ analysis of the course completion works on socio-scientific \\ issues, in a Pedagogy Program
}

\author{
Cinthia Leticia de Carvalho Roversi Genovese ${ }^{1}$ \\ https://orcid.org/0000-0002-5615-4004 \\ Washington Luiz Pacheco de Carvalho ${ }^{2}$ \\ https://orcid.org/0000-0002-1283-3021 \\ Luiz Gonzaga Roversi Genovese ${ }^{3}$ \\ https://orcid.org/0000-0002-7259-0519
}

\begin{abstract}
Resumo: Este estudo aborda a formação crítica de professores no ensino de Ciências e analisa desafios e potencialidades formativas da realização do Trabalho de Conclusão de Curso (TCC) por futuros pedagogos, na perspectiva da Educação, por meio das questões sociocientíficas, bem como busca estimular e promover, durante este processo, a subjetividade, a criatividade e a autoria dos sujeitos envolvidos. A partir dos conceitos teóricos de Theodor Adorno e dos dados obtidos por meio de notas de campo e de gravações das aulas foram criadas três dimensões: semiformativa, transição e dimensão formativa. Concluímos que a Educação, na perspectiva das questões sociocientíficas, contribuiu para a formação crítica em Ciências da Natureza de estudantes de pedagogia em formação, tanto para atuarem na docência, como no processo formativo da elaboração do TCC. Acreditamos que esta pesquisa também traz contribuições para compreender a construção da autonomia, da criatividade e da valorização da subjetividade na busca pela autoria no trabalho acadêmico.
\end{abstract}

Palavras-chave: Formação de professores. Curso de pedagogia. Ensino de ciências. Trabalho de conclusão de curso.

\begin{abstract}
This study addresses the critical education of teachers in Science teaching and analyzes challenges and formative potentials of the Course Completion Work (CCW) done by future educators, from the perspective of Education, through socio-scientific issues. It also seeks to stimulate and promote, during this process, the subjectivity, creativity and authorship of the subjects involved. Based on Adorno's theoretical concepts, and data obtained through field notes and class recordings, three dimensions were created: the half-education, transition and education dimensions. We conclude that education from the perspective of socio-scientific issues contributed to critical education in Nature Sciences to educators in training, both to act in teaching as well as in the educational process of producing the CCW. We believe that this research also brings contributions to explain the construction of autonomy, creativity and appreciation of subjectivity in the search for authorship in academic work.
\end{abstract}

Keywords: Teacher training. Science teaching. Pedagogy program. Course completion work.

\footnotetext{
${ }^{1}$ Universidade Federal de Goiás (UFG), Faculdade de Educação, Goiânia, GO, Brasil. E-mail: cinthialeticia@ufg.br

${ }^{2}$ Universidade Estadual Paulista (UNESP), Departamento de Física e Química, Ilha Solteira, SP, Brasil.

${ }^{3}$ Universidade Federal de Goiás (UFG), Instituto de Física, Goiânia, GO, Brasil.
} 


\title{
Introdução
}

A importância de lecionar Ciências nos anos iniciais do Ensino Fundamental foi reconhecida em nosso país a partir da publicação da Lei no 5.692, de 11 de agosto de 1971, que tornou obrigatório o ensino de Ciências da Natureza em todas as séries desse nível de escolaridade (BRASIL, 1971). Além de contribuir para o processo de leitura e escrita, bem como proporcionar o aprendizado dos conhecimentos básicos e suas aplicações no cotidiano, o ensino de Ciências também tem como função auxiliar os estudantes na compreensão das relações entre a Ciência e a sociedade e os meios de produção, e a apropriação dos saberes científicos e tecnológicos (FRACALANZA; AMARAL; GOUVEIA, 1986).

Atualmente, a Base Nacional Comum Curricular (BNCC) na área de Ciências da Natureza para os anos iniciais do Ensino Fundamental argumenta que, para o exercício da cidadania, é importante que os docentes trabalhem conteúdos a partir de "[...] questões que sejam desafiadoras e, reconhecendo a diversidade cultural, estimulem o interesse e a curiosidade científica dos alunos [...]" na definição e análise de problemas, bem como na representação de resultados e propostas de intervenções (BRASIL, 2017, p. 322, grifo nosso). Este documento oficial ainda afirma que os estudantes devem saber se posicionar sobre vários assuntos relacionados ao desenvolvimento científico e tecnológico e suas implicações na sociedade e no ambiente.

\begin{abstract}
Para debater e tomar posição sobre alimentos, medicamentos, combustíveis, transportes, comunicações, contracepção, saneamento e manutenção da vida na Terra, entre muitos outros temas, são imprescindíveis tanto conhecimentos éticos, políticos e culturais quanto científicos. Isso por si só já justifica, na educação formal, a presença da área de Ciências da Natureza, e de seu compromisso com a formação integral dos alunos (BRASIL, 2017, p. 317, grifo nosso).
\end{abstract}

Nesse sentido, a perspectiva da Educação por meio das questões sociocientíficas ${ }^{4}$ apresenta-se como uma possibilidade de lecionar Ciências da Natureza de maneira crítica e contextualizada, inserindo, nas discussões, em sala de aula, as implicações sociais, éticas e políticas da produção, divulgação e implementação do desenvolvimento da Ciência e da tecnologia. Trata-se de uma educação crítica em Ciências, cujo objetivo é formar cidadãos capazes de se posicionar de forma autônoma e cidadã, frente ao desenvolvimento tecnocientífico.

$\mathrm{Na}$ busca por esses propósitos formativos, esta pesquisa teve como objetivo compreender os desafios e as possibilidades de trabalhar o ensino de Ciências da Natureza com o tema das questões sociocientíficas, numa disciplina de Trabalho de Conclusão de Curso (TCC) de um curso de graduação em Pedagogia ofertado por uma universidade pública.

\footnotetext{
${ }^{4}$ Usamos neste artigo, prioritariamente, o termo questões sociocientíficas. No entanto, usamos também temas/assuntos controversos ou temas/assuntos sociocientificos quando nos referimos a esta mesma perspectiva de educação.
} 
Para que o trabalho fosse conduzido de maneira a proporcionar uma formação crítica, percebemos que as reflexões de Theodor Adorno sobre formação e semiformação seriam uma interessante possibilidade para que constituíssemos um referencial teórico que auxiliasse tanto na condução das orientações do trabalho acadêmico, como para as análises do processo formativo. Por fim, a partir dessas reflexões, elaboramos os seguintes questionamentos: "Quais os desafios e as potencialidades formativas da realização do TCC por futuros pedagogos, na perspectiva da Educação por meio das questões sociocientíficas? Como promover a subjetividade, a criatividade e a autoria neste processo?" 5

Antes da apresentação do referencial adorniano, faz-se necessária uma breve discussão acerca da perspectiva crítica das questões sociocientíficas no ensino de Ciências.

\section{Questões sociocientíficas: proposta crítica para o ensino de Ciências}

As questões sociocientíficas surgiram a partir do Movimento Ciência, Tecnologia e Sociedade (CTS). Muitos pesquisadores, devido ao crescente aumento da crise ambiental, preferem dar ênfase ao ambiente e utilizam a sigla CTSA em seus trabalhos de pesquisa (BORTOLETTO; CARVALHO, 2012; GALVÃO; REIS; FREIRE, 2011; MARCONDES et al., 2009; MARTÍNEZ PÉREZ, 2012; SASSERON; CARVALHO, 2008).

O Movimento CTS (ZIMAN, 1985) surgiu porque a sociedade passou a questionar os avanços científicos e tecnológicos apenas como benéficos à sociedade e ao ambiente. As bombas atômicas em Hiroshima e Nagasaki, a Guerra do Vietnã, os problemas decorrentes da poluição e do uso de agrotóxicos, entre outros, despertaram na população uma visão mais crítica sobre os impactos sociais e ambientais resultantes das pesquisas científicas.

Para viabilizar o trabalho em sala de aula com assuntos científicos controversos, Ratcliffe e Grace (2003) apresentaram as questões sociocientíficas como uma possibilidade de promover discussões e reflexões aos estudantes. Os autores explicam que as questões sociocientíficas são abertas e oportunizam diferentes opiniões, pois cada pessoa ou grupo de pessoas que se depara com um assunto científico polêmico vai enfrentar uma determinada situação de maneira diferente, com pontos de vista que podem divergir.

Opiniões sobre o consumo de alimentos transgênicos, gastos com pesquisa espacial, investimento em energia nuclear, liberação de mais agrotóxicos, obrigatoriedade da vacinação, uso de células-tronco embrionárias em pesquisas e tratamentos de doenças, alimentação vegetariana ou vegana são apenas alguns exemplos de assuntos científicos controversos que podem ser trabalhados nas aulas de Ciências para aprofundar conceitos e estimular o desenvolvimento da argumentação fundamentada de estudantes, a partir dos anos iniciais do Ensino Fundamental.

Sadler (2004) explica que as questões sociocientíficas não devem ser utilizadas para resolver um problema científico, pois o docente vai direcionar as discussões para contemplar as diversas opiniões dos estudantes, e não para forçar um consenso. Como vários dos assuntos

\footnotetext{
${ }^{5}$ Apesar de a pergunta ter sido direcionada a futuros pedagogos e pedagogas, esta pesquisa foi realizada apenas com estudantes do sexo feminino.
} 
mencionados anteriormente são abordados nos meios de comunicação, cabe ao docente apresentar e discutir os diversos interesses que podem estar presentes em cada uma das notícias veiculadas.

No Brasil há diversas pesquisas sobre as questões sociocientíficas na formação inicial e continuada de professores da área de Ciências (BORTOLETTO; CARVALHO, 2012; GALVÃO; REIS; FREIRE, 2011; GUIMARÃES, 2011; MARTÍNEZ PÉREZ; CARVALHO, 2012; REIS, 2004; REIS; GALVÃO, 2008; SANTOS; MORTIMER, 2009). No entanto há poucos estudos que abordam as questões sociocientíficas no trabalho, em sala de aula, com estudantes dos anos iniciais do Ensino Fundamental, ou na formação de pedagogos.

Um estudo que merece destaque é o de Vissicaro, Figueirôa e Araújo (2016), que elaboraram e implementaram uma sequência didática para estudantes do $3^{\circ}$ e $4^{\circ}$ anos do Ensino Fundamental. A questão sociocientífica formulada e trabalhada abordava o tema água, e a escolha por este assunto foi motivada pela falta de água enfrentada pela região Sudeste em 2015.

As autoras relataram que trabalharam com diferentes reportagens para demonstrar que a falta de água é um assunto complexo e que não há um único motivo que explique essa situação. Desse modo, estimularam discussões que valorizavam as diferentes falas dos estudantes, a fim de que eles tivessem a oportunidade de se manifestarem e se posicionarem frente a essa questão. A importância da formação do professor também foi mencionada pelas pesquisadoras, pois estas salientaram que muitas vezes o docente não se sente preparado para coordenar diálogos e discussões que favoreçam a formação crítica, ou seja, uma formação voltada para a autonomia.

Sobre a importância da formação crítica de professores, apresentaremos, a seguir, o referencial teórico que escolhemos para fundamentar este trabalho.

\section{Formação e semiformação cultural a partir da teoria da semicultura de Adorno}

Este trabalho aborda a formação crítica de professores no ensino de Ciências. O conceito de formação que o fundamenta possui suas bases na Teoria Crítica, em especial nas contribuições de Theodor Adorno, que traz explicações que coadunam com nossas intenções. Como este conceito abrange outros setores da sociedade, além da escola, o autor traz vários exemplos para ilustrar sua preocupação com a semiformação cultural a que praticamente todos estão sujeitos.

Segundo Adorno (1996), a formação (Bildung) é a apropriação subjetiva da cultura. Nessa apropriação cultural, o indivíduo valoriza seus gostos e sentimentos, relacionando-os ao mundo real. Ele conhece seu papel histórico e social e sabe que pertence a uma determinada comunidade. A partir dos valores aprendidos na coletividade, esse sujeito vai elaborar seus próprios valores, apropriando-se subjetivamente da cultura da sociedade em que vive.

Porém, como a nossa cultura está imersa em um mecanismo ideológico denominado indústria cultural (ADORNO, 1996), acabamos por viver numa sociedade cuja cultura converte-se em semicultura, ou seja, a desarticulação das condições subjetivas impede a emancipação para a formação. Conforme Maar (2003), isso significa que os indivíduos, enquanto sujeitos, aceitam e alimentam o processo de sua própria alienação, reproduzindo o mundo na condição de sujeitos sujeitados. 
É a indústria cultural que direciona as reflexões que Adorno (1996) faz ao nos mostrar o quanto a semiformação (Halbbildung) está presente, levando as pessoas ao conformismo e ao imediatismo. E essa situação é tão profunda e ampla ao mesmo tempo, que a escola e as reformas pedagógicas isoladas, embora necessárias, não são suficientes para combater essa indústria, já que esta atinge todos os setores e camadas sociais e intelectuais.

As reformas pedagógicas isoladas que "[...] revelam uma inocente despreocupação diante do poder que a realidade extrapedagógica exerce [...]" (ADORNO, 1996, p. 388) podem até reforçar a crise da formação cultural, pois abrandam as exigências que deveriam ser feitas aos educandos. O autor também argumenta que as investigações e as reflexões sobre os fatores que influenciam positiva ou negativamente a formação cultural também não trazem contribuições significativas, se forem realizadas isoladamente dos aspectos que relacionam o conceito de formação com as implicações sociais.

Por conseguinte, o objetivo da Educação para a emancipação envolve a crítica à semiformação. Essa crítica acontece quando o indivíduo é capaz de enxergar as enormes dificuldades nas contradições sociais presentes no mundo. Por exemplo, o controle planificado que a indústria cultural exerce é algo muito difícil de ser esquivado (ADORNO, 1995a; MAAR, 2003). A manipulação inteligente e perspicaz realizada pelos jornalismos televisivos e impressos só não aliena as pessoas que realmente tiveram e têm algum conhecimento teórico sobre História e Sociologia, entre outras áreas, e que conseguem fazer alguma reflexão sobre a quem as informações veiculadas servem.

Assim, a socialização do indivíduo acaba, de certa forma, prejudicando-o, porque a formação cultural atual, transformada em semiformação, tem como objetivo a alienação.

A formação cultural agora se converte em uma semiformação socializada, na onipresença do espírito alienado, que, segundo sua gênese e seu sentido, não antecede à formação cultural, mas a sucede. Desse modo, tudo fica aprisionado nas malhas da socialização (ADORNO, 1996, p. 389).

O acesso a informações cada vez mais difundidas na sociedade de massa não colabora na formação cultural dos sujeitos. Ela "deforma" a consciência atual, alienando os indivíduos. Dessa maneira, a cultura não mais liberta, porque os bens culturais foram transformados em mercadorias, cujos produtos levam à dissociação progressiva da consciência (ADORNO, 1996). Tal dissociação ocorre porque os bens culturais acabaram ficando descontextualizados dos fazeres humanos. Portanto o estudo dos conteúdos escolares isolados são elementos da semiformação.

Para Adorno (1996), a semiformação é uma espécie de "formação regressiva” porque os produtos da indústria cultural levam a sociedade a um estado adaptativo que fortalece a ideologia de se conformar ao que está posto, impedindo que as pessoas eduquem umas às outras.

Desse modo, os indivíduos acabam por suportar e se conformar com as relações de poder e com as condições desfavoráveis do próprio trabalho, deixando que se perpetue “[...] o esquema da dominação progressiva” (ADORNO, 1996, p. 391), que é constantemente alimentado por uma espécie de formação que "[...] é diferente de época para época por seu conteúdo e suas instituições” (ADORNO, 1996, p. 391).

Como mencionado, isso pode ser percebido quando se analisa a mídia de massas. Os muitos mecanismos midiáticos, ao oferecerem seus bens culturais que levam à semiformação, 
ao mesmo tempo também fazem os sujeitos se sentirem integrados à sociedade. Na realidade, essa integração é um mecanismo para petrificá-los e neutralizá-los, a fim de mantê-los em seus devidos lugares, consumindo produtos cada vez mais (ADORNO, 1996).

[...] a indústria cultural, em sua dimensão mais ampla - tudo o que o jargão específico classifica como mídia -, perpetua essa situação, explorando-a, e se assumindo como cultura em consonância com a integração, o que, se for mesmo uma, não será a outra. Seu espírito é a semicultura, a identificação (ADORNO, 1996, p. 396, grifo do autor).

O autor, no entanto, explica que a integração, por ser uma ideologia, é frágil e desmoronável. O único conceito que serve de antítese à semicultura é, ainda que questionável, a formação cultural tradicional. Isso não significa um retrocesso ao passado nem o abrandamento à sua crítica, cujos conteúdos não tinham relações vivas com o sujeito.

Também não se pode afirmar que a semiformação cultural esteja em todos os níveis sociais indiscriminadamente, mas que se trata de uma tendência (ADORNO, 1996). Além disso, "nadar contra a correnteza" pode ser desgastante, já que "[...] aquele que pensa, opõe resistência; é mais cômodo seguir a correnteza, ainda que declarando estar contra a correnteza." (ADORNO, 1995b, p. 208).

Assim, conforme o autor, é possível que grupos de trabalhadores que possuam uma consciência de classe não se deixem envolver pelos mecanismos semiformativos. Porém, esses mecanismos são tão intrusivos e insistentes e se alinham tão imbricadamente à cultura atual, que fica difícil não ser envolvido por suas malhas, já que “[...] os 'homens’ aderem pelos efeitos desta adesão: na sociedade que se reproduz destacam-se os que aderiram." (MAAR, 2003, p. 265).

A proteção perante as atrações do mundo poderia ser maior se as reformas escolares não tivessem enfraquecido a necessidade de "[...] dedicação e o aprofundamento íntimo do espiritual, a que estava vinculada a liberdade.” (ADORNO, 1996, p. 397). Nesse aspecto, o autor defende o estudo da poesia e da filosofia, já que com sua exclusão, “[...] se priva o intelecto e o espírito de uma parte do alimento de que se nutre a formação.” (ADORNO, 1996, p. 398).

Semiformados, os indivíduos são mais suscetíveis aos apelos consumistas, que adulteram também a vida sensorial por meio de propagandas e de programas com mulheres e homens com uma beleza estonteante, tornando o "[...] espírito conquistado pelo caráter de fetiche da mercadoria [...]" (ADORNO, 1996, p. 400) e transmitindo a mensagem “[...] de como pode o sujeito resistir a uma racionalidade que, na verdade, é em si mesma irracional." (ADORNO, 1996, p. 400).

Dessa forma, um grande setor do mercado da indústria cultural vive de lançar publicações que vendem uma ideologia pseudodemocrática. Isso é verificado em enciclopédias sintetizadas, almanaques, além das resenhas e resumos de livros. Eles são interessantes para uma informação inicial, se, depois, houver o aprofundamento. Há também as biografias romanceadas, empobrecidas com futilidades, e não se pode deixar de mencionar que se ter um CD ou DVD de uma orquestra não é a mesma coisa de assistir a um concerto ao vivo, algo que é profundamente diferente para o espírito humano (ADORNO, 1996).

O objetivo ideológico é vender a ideia de "facilitar" a formação cultural por um caminho mais rápido e fácil. Essa estrutura reproduz e reforça a ignorância, ou seja, a semiformação 
dos indivíduos. Se não é possível se opor a esses mecanismos facilitadores, também não se deve deixar de perceber suas implicações para a compreensão limitada dos conteúdos, tanto das obras literárias, artísticas e musicais, quanto dos conhecimentos científicos.

\begin{abstract}
De fato, seria insensato querer segregar tais textos em edições científicas, em edições reduzidas e custosas, quando o estado da técnica e o interesse econômico convergem para a produção massiva. Isso não significa, porém, que se deva ficar cego, por medo do inevitável, diante de suas implicações, nem, sobretudo, diante do fato de que entra em contradição com as pretensões imanentes de democratizar a formação cultural [...] que se socializa como semiformação (ADORNO, 1996, p. 402).
\end{abstract}

No entanto, Adorno (1996) entende que, quando se resumem obras tanto artísticas, como científicas, seus conteúdos acabam sendo entendidos parcialmente e podem, até mesmo, ser deturpados e mal interpretados, fortalecendo a reificação da consciência, ou seja, sua passividade, seu automatismo, seu conformismo, que precisamente é o que deveria ser combatido pela formação.

A semiformação traz também a concepção de que algumas pessoas já nascem dotadas de talento e genialidade e que realizam seus feitos de maneira fácil e fluida. Porém trata-se de “[...] uma concepção enganosa. Nada do que, de fato, se chame formação poderá ser apreendido sem pressupostos." (ADORNO, 1996, p. 403).

Quando a indústria cultural passa a informação de que algumas pessoas são mais geniais do que outras, ela está plantando profundamente o espírito do conformismo, já que, se não é o esforço que cria o gênio, então por que se esforçar? É muito mais fácil e aceito socialmente dizer que não se tem boa memória e que possui infinitas ocupações, justificando a falta de tempo. Em filmes ou séries para a televisão, as personagens que apreciam a leitura ou que gostam de Matemática ou Química, por exemplo, são apresentadas como muito inteligentes e, frequentemente, como indivíduos que têm algum problema de relacionamento com outras pessoas.

Como os mecanismos da indústria cultural atingem a subjetividade do indivíduo, Adorno também faz uma análise psicológica de como estes o afetam. O semiculto inconscientemente sabe de sua própria condição, o que o deixa ressentido, mas também conformista, pois, ao "[...] mesmo tempo em que se apossa fetichisticamente dos bens culturais, está sempre na iminência de destruí-los." (ADORNO, 1996, p. 406).

Essa situação faz com que o semiculto adquira uma postura defensiva e imediatista. A falta de consciência dos problemas políticos, sociais, econômicos e ambientais faz com que o semiculto transforme, "[...] como que por encanto, tudo o que é mediato em imediato [...]" (ADORNO, 1996, p. 407), manifestando um comportamento de quem tem pressa e valoriza qualquer informação nova, mesmo que fútil ou inútil. O semiculto se sente valorizado quando consegue demonstrar que é o primeiro a divulgar algum acontecimento.

Existe um controle no jogo de forças de vários setores da sociedade, voltados para o mercado, que impede que o indivíduo compreenda o que poderia ser completamente compreendido. Isso produz uma sensação tão desagradável, de não conseguir despertar frente o poder existente, que "[...] paralisa até os movimentos que impelem ao conhecimento." (ADORNO, 1996, p. 407). 
Quando a informação se refere a uma crítica presente na mídia, esta não é emancipadora e reflexiva sobre os poderes estabelecidos. A crítica midiática geralmente acontece contra os próprios adversários políticos que estão eleitos no momento. Portanto, como a visão social está deturpada e camuflada, a semiformação se apresenta "[...] isenta de responsabilidades [...]" (ADORNO, 1996, p. 408) e insensível “[...] diante das catástrofes da história como seu próprio inconsciente.” (ADORNO, 1996, p. 408).

É comum ver em nosso país grande parte da mídia televisiva e impressa veicular informações incompletas, deturpadas e, muitas vezes, incorretas sobre adversários políticos que não atendem aos interesses de uma pequena parcela da população. As pessoas que não buscam informações em meios alternativos acabam acreditando e defendendo o ponto de vista disseminado pelas grandes corporações da mídia brasileira, administradas por algumas famílias que detêm seu controle.

Dessa forma, o espírito neutralizado destrói a formação cultural, dificultando a possibilidade pedagógica de mudança, que, isolada, não consegue atuar na transformação da consciência. Sobre essa constatação de Adorno, que enxerga a semiformação como sujeita ao capitalismo, Maar argumenta que: "Adorno, ao contrário do resignado pessimismo equivocadamente associado com sua obra, apresenta uma alternativa prática real para a tendência à totalização social dominante, ao revelar a construção objetiva da formação social presente" (MAAR, 2003, p. 467).

Para isso, é preciso refletir sobre a formação cultural, não tornando a cultura sagrada, dogmatizada, fetichizada, tampouco ser eliminada. É preciso que o espírito realize o socialmente justo, pois a "[...] única possibilidade de sobrevivência que resta à cultura é a autorreflexão crítica sobre a semiformação, em que necessariamente se converteu." (ADORNO, 1996, p. 410), com o financiamento da indústria cultural.

Defendemos a importância da compreensão do conceito de indústria cultural num trabalho sobre Educação na perspectiva crítica porque:

A semiformação vai muito além de uma 'perturbação pedagógica' no interior de uma determinada situação social educacional. Refere-se a uma forma ordenada da sociedade contemporânea determinada conforme um certo modo de produção social dos homens, e somente neste âmbito pode ser adequadamente apreendida (MAAR, 2003, p. 471).

O processo de semiformação se instala quando a produção cultural simbólica se afasta de suas origens para servir aos interesses capitalistas de consumo. Esse processo, promovido pela indústria cultural, anula as manifestações de subjetividade que proporcionam ao indivíduo a autonomia e a emancipação para a formação.

A construção social e histórica da produção da Ciência e da tecnologia e seus impactos na sociedade são refletidos neste trabalho sobre formação de professores para o ensino de Ciências. Nesse sentido, acreditamos no potencial dos pedagogos para abordarem essa perspectiva no ensino de Ciências, por serem profissionais cuja formação inicial é estruturada com a presença de disciplinas de várias áreas do conhecimento. 


\section{Trajeto metodológico}

Esta pesquisa qualitativa teve a participação de onze estudantes de graduação em Pedagogia, que se matricularam nas disciplinas semestrais de "TCC I" e/ou "TCC II", ministradas pela primeira autora deste trabalho no período noturno de uma universidade pública. Essas disciplinas correspondiam à área de Ciências da Natureza, cujo tema eram as questões sociocientíficas na Educação Infantil, anos iniciais do Ensino Fundamental e Educação de Jovens e Adultos (EJA).

Para Bogdan e Biklen (2010), os dados de uma pesquisa são todo o material em estado bruto que formam a base da análise. Desse modo, para atender aos objetivos deste estudo, os dados constituídos foram notas de campo durante as aulas e as transcrições das gravações em áudio de todas as aulas nas disciplinas de "TCC I" e "TCC II", que foram ministradas no ano de 2015. As estudantes assinaram o Termo de Consentimento Livre e Esclarecido, respeitando-se todas as etapas desse processo.

A teoria de Adorno desenvolvida na seção anterior como referencial teórico foi utilizada também como referencial metodológico, pois os dados obtidos por meio das falas das estudantes foram categorizados a partir dessa teoria. Assim, procedemos ao rigor da objetividade teórica articulado à fertilidade da subjetividade, pois atrás de uma fala pode esconder-se um sentido que é necessário desvendar, a fim de se interpretarem e se analisarem os dados.

Os nomes das alunas participantes foram substituídos por nomes fictícios de personagens da mitologia grega, a saber: Afrodite, Artêmis, Atena, Deméter, Hera, Hígia, Íris, Nêmesis, Nice, Tálassa e Tália. Das onze estudantes, oito concluíram os trabalhos. A seguir, apresentamos o Quadro 1, no qual relacionamos as características das personagens mencionadas às personalidades das alunas ou ao tema com que cada uma escolheu trabalhar no TCC.

Quadro 1 - Articulação dos nomes fictícios às estudantes

\begin{tabular}{|l|l|l|}
\hline \multicolumn{1}{|c|}{ Nome } & \multicolumn{1}{|c|}{ Algumas características } & \multicolumn{1}{c|}{ Relações com cada estudante } \\
\hline 1. Afrodite & Amor, beleza, sexualidade. & $\begin{array}{l}\text { Muito cuidadosa com seus cabelos, que foi a } \\
\text { origem de seu tema. Amorosa e compreensiva com } \\
\text { as colegas. }\end{array}$ \\
\hline 2. Artêmis & Vida selvagem, luta, caça. & $\begin{array}{l}\text { Educada, gentil e extremamente determinada e } \\
\text { lutadora. Era inconformada com o uso excessivo } \\
\text { da Ritalina. }\end{array}$ \\
\hline 3. Atena & $\begin{array}{l}\text { Habilidosa e articulada para defender seus pontos } \\
\text { de vista, sendo, às vezes, um pouco combativa. }\end{array}$ \\
\hline 4. Deméter & Agricultura, colheitas. & $\begin{array}{l}\text { Calma e gentil, trabalhou com o tema sobre os } \\
\text { alimentos transgênicos. }\end{array}$ \\
\hline 5. Hera & $\begin{array}{l}\text { Casamento, maternidade. } \\
\text { Retratada como majestosa e } \\
\text { solene, pois era a rainha do } \\
\text { Olimpo. }\end{array}$ & $\begin{array}{l}\text { Muito confiante em seus gestos e falas, ia às aulas } \\
\text { muito arrumada. Sempre gentil, não deixava de dar } \\
\text { sua opinião sobre qualquer assunto. }\end{array}$ \\
\hline
\end{tabular}


Quadro 1 - continuação

\begin{tabular}{|l|l|l|}
\hline \multicolumn{1}{|c|}{ Nome } & \multicolumn{1}{|c|}{ Algumas características } & \multicolumn{1}{c|}{ Relações com cada estudante } \\
\hline 6. Hígia & Saúde, limpeza, sanidade. & $\begin{array}{l}\text { Extremamente calma, tranquila e centrada. } \\
\text { Demonstrava inteligência e iniciativa. Era contra o } \\
\text { uso abusivo da Ritalina. }\end{array}$ \\
\hline 7. Íris & $\begin{array}{l}\text { Arco-íris, mensageira dos } \\
\text { deuses e ajudava Hera em suas } \\
\text { vinganças. Equilibrada e calma, } \\
\text { evitava o confronto. }\end{array}$ & $\begin{array}{l}\text { Muito bonita, falava sobre seu tema - a Ritalina- } \\
\text { com desenvoltura, conhecimento e brandura, mas } \\
\text { não realizou a produção escrita. }\end{array}$ \\
\hline 8. Nêmesis & $\begin{array}{l}\text { Vingança divina, justiça divina, } \\
\text { destino. }\end{array}$ & $\begin{array}{l}\text { Apresentava determinação muito forte para fazer o } \\
\text { curso de Nutrição. }\end{array}$ \\
\hline 9. Nice & Velocidade. & Faltava muito e desistiu da disciplina rapidamente. \\
\hline 10. Tálassa & Mar (Mediterrâneo) & Apresentava personalidade calma e tranquila. \\
\hline 11. Tália & Comédia & Muito alegre, divertida, esforçada e otimista. \\
\hline
\end{tabular}

Fonte: elaborado pelos autores.

$\mathrm{Na}$ exploração inicial do material, a codificação dos dados foi realizada a partir dos momentos em que as estudantes manifestaram suas inseguranças, suas dificuldades, suas compreensões e seus avanços. Na pesquisa qualitativa, as falas, as percepções, as expressões e os comportamentos dos sujeitos são de vital importância, por isso os dados mais relevantes que foram agrupados em dimensões e categorias foram as falas das estudantes a partir do início da elaboração do TCC, com algumas anotações quando havia, por exemplo, sorrisos, risos ou expressões de tristeza e decepção. A partir dos dados obtidos, foram criadas três dimensões: Dimensão Semiformativa, Dimensão de Transição e Dimensão Formativa, tendo como principal fundamento os conceitos de formação e semiformação de Adorno.

$\mathrm{Na}$ Dimensão Semiformativa, agrupamos as falas em que as estudantes demonstraram situações de insegurança, medo, mas principalmente a busca por facilitações, sem a dedicação e o esforço necessários para uma formação docente mais significativa. Conforme explica Adorno (1996), o semiculto tende a transformar, como se fosse um encanto, em imediato tudo o que é mediato, incluindo até as coisas e situações mais distantes.

A partir da leitura cuidadosa dos dados encontrados nesta pesquisa, percebemos que, entre a semiformação e a formação, há um caminho a ser percorrido. Esse caminho, denominado Dimensão de Transição, apresenta elementos que indicam a tentativa e o esforço para a formação. Também é caracterizado por situações de aceitação ou de rejeição aos desafios formativos que as estudantes tiveram que enfrentar. Consideramos como elemento de transição o esforço e a dedicação de uma estudante ao seu trabalho, por sua motivação ter característica semiformativa, dado o interesse em obter uma nota alta. Outro aspecto considerado como transição foi a escolha do tema sociocientífico para a elaboração do TCC.

Classificamos como pertencentes à Dimensão Formativa as falas em que as estudantes se mostraram mais autônomas com relação ao próprio trabalho e à visão que manifestaram como futuras professoras e seu papel na sociedade. 


\section{Apresentação e discussão dos dados}

Esta pesquisa teve como propósito relacionar e analisar o processo de elaboração do TCC sobre questões sociocientíficas realizado por pedagogas em formação, na perspectiva dos referenciais teóricos utilizados neste estudo, ou seja, os conceitos de formação e semiformação de Adorno. Os dados são extensos e estão inseridos em um contexto formativo complexo, que é o da criação de um trabalho acadêmico. Por isso, alguns trechos de falas foram selecionados, mas optamos por deixar outros trechos completos para que o leitor possa compreender o contexto da fala das futuras docentes. As palavras ou expressões sublinhadas foram as que as alunas deram muita ênfase ao pronunciá-las.

\section{Dimensão Semiformativa}

Insegurança. A insegurança é gerada pelo sistema para o indivíduo sempre seguir as regras, as normas, para se adequar, pois está inseguro. Esse comportamento torna a pessoa obediente e leal, inclusive à economia capitalista. Na disciplina “TCC I", houve uma atividade em que cada estudante deveria procurar e escolher um artigo sobre uma questão sociocientífica ou tema controverso. Nêmesis fala sobre sua insegurança antes de apresentar o artigo escolhido: "Eu vou pedir desculpas, porque eu estou com medo de apresentar o artigo. Pensei muito em desistir, porque... nossa! É um desafio muito grande. O texto é muito longo."

O medo de errar, de ser ridículo e de não ser aprovado são frutos da indústria cultural que deseja indivíduos exatamente assim. Quem é inseguro consome muito mais produtos na ilusão de se autoafirmar, de fazer parte do grupo. De acordo com Feitosa (2017), em geral, os estudantes universitários ficam apreensivos e estressados na época de desenvolverem o TCC.

Busca por facilitações. Essa busca pode estar intimamente relacionada a um processo educacional semiformativo, que não exige criatividade e autonomia do estudante. Isso significa que o sujeito não é valorizado, a sua opinião não importa, não é relevante. Como não está preparado para fazer suas próprias escolhas, acaba buscando tudo o que for mais fácil, rápido e cômodo.

$\mathrm{Na}$ etapa sobre as orientações finais do TCC, as estudantes fizeram perguntas sobre as apresentações e a elaboração dos slides.

\footnotetext{
Atena: Professora, no capitulo I, a gente vai fazer o quê??

Professora: Você vai colocar alguma citação, um pedaço do texto. Você quem vai escolber.

Atena: Ah não, professora! Esse negócio de "você que escolhe" eu não gosto não.

Professora: Coloque as partes que você achar mais importante.

Atena: Não vou falar mais nada não...
}

A estudante não queria selecionar o que achava mais importante para elaborar seus próprios slides. Ela queria que a professora orientadora escolhesse por ela, porque ler cada capítulo e selecionar o que será mencionado nos slides é uma atividade que demanda esforço e tomada de decisão. Isso quer dizer que, praticamente no final da disciplina "TCC”, a estudante 
Genovese, C. L. C. R.; Carvalho, W. L. P.; Genovese, L. G. R.

ainda procurou por respostas prontas, o que nos sugere que a educação formativa pode ser um processo longo.

\title{
Dimensão de Transição
}

Esforço e dedicação com motivação semiformativa. No segundo semestre, durante a disciplina "TCC II", uma fala da estudante Artêmis chamou nossa atenção. Essa aluna realizou seu trabalho com interesse e esforço, apesar de demonstrar algumas dificuldades em alguns aspectos.

\begin{abstract}
Artêmis: Professora, amanhã te enviarei. Se tiver errado, a senhora fala: 'Artêmis, apaga tudo! Faça tudo de novo!' Eu prefiro apagar tudo e fazer tudo de novo do que chegar aqui, na hora da apresentação, e tirar um sete. Eu vou morrer se eu tirar um sete! Porque eu não tenho dia, não tenho noite, não tenho nada. Porque assim: a Beatriz. dormiu, que era o momento de eu descansar; eu vou fazer o TCC. Então, assim, eu preciso que a senhora fale para eu dizer: 'Uh! Valeu a pena!' Então, pelo amor de Deus, pode falar professora.
\end{abstract}

Depois desta fala, percebemos que a dedicação de Artêmis para aprender e realizar seu trabalho estava muito relacionada à preocupação com a nota. Mesmo que seus motivos fossem acríticos e semiformativos, seu esforço também pode ser considerado uma característica da formação.

Entretanto, para Horkheimer (1983), esse tipo de pensamento e de ação está em desacordo com o pensamento crítico, porque a estudante estava disposta a fazer qualquer sacrifício para tirar nota alta. Ela afirmou que aceitaria o esforço sem contestação, submissamente, pois a honra da nota alta era o que a estudante buscava. Possivelmente, Artêmis tenha agido dessa maneira durante todo o curso de Pedagogia, pois a estudante declarou que poderia ter escolhido qualquer TCC por causa de sua média global, ou seja, era uma estudante acostumada a tirar notas altas.

$\mathrm{Na}$ instituição onde esta pesquisa foi realizada, alunos com notas maiores têm prioridade nas escolhas de algumas disciplinas, como "TCC", que tem o limite máximo de dez alunos. Para Adorno (1996), essas estruturas objetivas aniquilam a formação, pois contribuem para destruir a liberdade e a autonomia, já que os estudantes se submetem ao conformismo e à aceitação para conseguir uma formação. No entanto, em nosso ponto de vista, Adorno propõe um desafio, que é o de obter uma formação cultural sob as influências e imposições das estruturas semiformativas objetivas, às quais também nós estamos submetidos ainda que conscientes delas.

Escolha do tema. Consideramos a escolha do assunto a ser desenvolvido no TCC uma característica de transição para a formação. Apesar de não ter havido liberdade total, já que o tema deveria ter a possibilidade de ser trabalhado como uma questão sociocientífica, procuramos valorizar ao máximo o aspecto subjetivo apresentado por cada aluna. Como não expusemos todas as falas sobre as escolhas dos temas sociocientíficos, elencamos no quadro 2, os temas escolhidos pelas estudantes, as origens de suas escolhas e o nível de ensino. 
Quadro 2 - Assuntos controversos escolhidos pelas estudantes

\begin{tabular}{|l|l|l|l|}
\hline Estudante & \multicolumn{1}{|c|}{$\begin{array}{c}\text { Assunto controverso } \\
\text { escolhido }\end{array}$} & $\begin{array}{c}\text { Origem da motivação pela } \\
\text { escolha }\end{array}$ & \multicolumn{1}{|c|}{ Nível de ensino } \\
\hline 1. Afrodite & $\begin{array}{l}\text { Xampu-bomba com Monovin } \\
- \text { A. }\end{array}$ & Motivação pessoal & EJA \\
\hline 2. Artêmis & Ritalina. & Vivência como docente & Professores e gestores \\
\hline 3. Atena & Fast-food, refrigerantes e a mídia. & Motivação pessoal & Educação Infantil \\
\hline 4. Deméter & Os alimentos transgênicos. & Motivação pessoal & EJA \\
\hline 5. Hera & Clareamento dentário. & Motivação pessoal & EJA \\
\hline 6. Hígia & Ritalina. & Vivência como docente & Professores e gestores \\
\hline 7. Íris & Ritalina. & Vivência como docente & Professores e gestores \\
\hline 8. Nêmesis & $\begin{array}{l}\text { Descarte inadequado de } \\
\text { medicamentos. }\end{array}$ & Motivação pessoal & EJA \\
\hline 9. Nice & $\begin{array}{l}\text { Descarte inadequado de pilhas } \\
\text { e baterias. }\end{array}$ & Motivação pessoal & EJA \\
\hline 10. Tálassa & $\begin{array}{l}\text { Alimentos industrializados } \\
\text { no lanche escolar (TCC I) e } \\
\text { Ritalina } \text { (TCC II). }\end{array}$ & Vivência como docente & $\begin{array}{l}\text { Anos iniciais do } \\
\text { Ensino Fundamental / } \\
\text { Professores e gestores }\end{array}$ \\
\hline 11. Tália & $\begin{array}{l}\text { Carro elétrico. } \\
\text { Vjência como funcionária de } \\
\text { uma empresa de logística. }\end{array}$ & EJA \\
\hline
\end{tabular}

Fonte: elaborado pelos autores.

Quanto à origem da motivação pela escolha do tema; para seis estudantes, a motivação foi por interesse pessoal, e, para cinco estudantes, por causa da vivência profissional, sendo cinco como docentes e uma como funcionária de uma empresa. Toda escolha é pessoal, mas a separação que decidimos fazer realizou-se porque, no momento de se referirem ao assunto escolhido, as alunas se remetiam a aspectos pessoais ou profissionais. O mundo capitalista administrado por meio da indústria cultural interfere de maneira significativa sobre diversas escolhas que fazemos ao longo da vida. É possível perceber o quanto os padrões de beleza, estética, moda, hábitos de consumo e comportamento influenciaram as escolhas que as estudantes fizeram sobre os temas.

\section{Dimensão Formativa}

Busca pela autoria e autonomia. A palavra autonomia pode ter diferentes significados de acordo com três concepções sobre a profissão docente, ou seja, três modelos de professores (CONTRERAS, 2002). Para o primeiro modelo, o especialista técnico, a autonomia se apresenta como status: o professor depende de diretrizes técnicas e é incapaz de ser criativo diante de incertezas. A autonomia do segundo modelo, o profissional reflexivo (SCHÖN, 2000), é tida como uma responsabilidade moral e social. O professor considera diferentes 
pontos de vista e é capaz de resolver as situações de maneira criativa. Já o professor intelectual crítico (GIROUX, 1997), terceiro modelo, concebe a autonomia como emancipação, pois consegue superar as distorções ideológicas por meio de sua consciência crítica. Esse profissional trabalha no intuito de transformar as condições sociais e institucionais do ensino.

O significado de autonomia que buscamos está mais próximo do professor intelectual crítico, porque a independência intelectual ocorre quando há emancipação do indivíduo frente às imposições externas. Quando algumas estudantes decidiram sobre diferentes aspectos relacionados ao próprio trabalho, elas atribuíram um sentido e um significado, sem dependerem de nossa permissão para realizarem algumas modificações.

Nêmesis: Em um dos meus rascunhos, coloquei: 'Disposição inadequada dos lixos: para onde vão os medicamentos?' [...] No começo do meu texto, eu vou falar sobre o lixo. Depois eu vou falar sobre outros lixos que também têm o descarte inadequado. Aí eu pontuo só na questão dos medicamentos. Pensei em ligar tanto a primeira parte quanto a segunda.

Nêmesis apresentou muito bem o título de seu trabalho, explicando até as palavras escolhidas, demonstrando apropriação do que ela havia proposto desenvolver.

Vendo-se e pensando como professora. No último dia de aula, as alunas estavam comentando que, quando foram imprimir o TCC, algumas pessoas perguntavam qual era o título e, quando aquelas respondiam, as pessoas se assustavam.

Hera: Inclusive a gente estava imprimindo o TCC, e uma menina estava lá e perguntou o tema. Ela se assustou e perguntou qual era o curso. Pedagogia todo mundo pensa que é só brincar. O papel do professor é o de ajudar o aluno a pensar e ter sua opinião própria. Nós que estamos saindo agora temos uma formação diferente de quem já se formou bá 20 anos.

Muitos TCC apresentados no curso de Pedagogia da instituição onde a pesquisa foi realizada são desenvolvidos com abordagens voltadas para o trabalho lúdico com as crianças. Adorno (1995c) explica que o professor sofre um certo desprezo por estar inserido no mundo infantil, não sendo, portanto, considerado totalmente um adulto. Em sua fala, Hera demonstrou que pretende lutar para modificar a situação descrita.

Nesse mesmo dia questionamos se o TCC, de alguma forma, contribuiu para a formação das alunas como professora, Hera respondeu.

Hera: Eu... só virei professora, praticamente. [Risos de todas]. Em janeiro [2015] eu era analista de estratégia e em agosto [do mesmo ano] eu decidi voltar para a docência. Eu nem deveria ter saído. Tenho planos para melhorar, inclusive eu entrei na pós-graduação [especialização] também porque era uma coisa que en queria fažer. Para minha formação como professora, como alguém crítico, com consciência crítica foi muito importante porque me ajudou bastante na questão da escolba, em acreditar que a gente pode fazer coisas diferentes, que a educação não tem que ser algo engessado; depende do professor. Então isso foi muito importante para mim. 
Hera se posicionou como uma pessoa com "consciência crítica” e que, como educadora, "pode fazer coisas diferentes". A estudante voltou a lecionar e se matriculou num curso de especialização, para continuar se dedicando à docência e a sua própria formação.

Concordamos com Horkheimer (1983) quando este autor defende que faz parte do desenvolvimento da sociedade o comportamento crítico e consciente. O protesto contra a ordem inerente do mecanismo econômico é o produto necessário do desenvolvimento histórico, em que as ações humanas partem de suas próprias decisões, de sua autodeterminação, e não mais de um mecanismo imposto.

A seguir, apresentamos, por meio do Quadro 3, as questões sociocientíficas formuladas por cada graduanda seguidas dos títulos de seus TCC.

Quadro 3 - Questões sociocientíficas e títulos dos TCC das estudantes*

\begin{tabular}{|c|c|c|}
\hline Estudante & Questão sociocientífica & Título do TCC \\
\hline 1. Afrodite & $\begin{array}{l}\text { O modismo do xampu-bomba: até onde ir para } \\
\text { alcançar o padrão de beleza? }\end{array}$ & $\begin{array}{l}\text { Estética e Monovin-A: uma proposta de ensino } \\
\text { para a educação de jovens e adultos. }\end{array}$ \\
\hline 2. Artêmis & $\begin{array}{l}\text { Ritalina: diagnóstico precário ou resposta das } \\
\text { novas exigências contemporâneas? }\end{array}$ & $\begin{array}{l}\text { As controvérsias sobre os diagnósticos e } \\
\text { uso da ritalina: uma proposta de análise e } \\
\text { discussão em uma formação continuada de } \\
\text { professores. }\end{array}$ \\
\hline 3. Atena & $\begin{array}{l}\text { A influência da mídia no consumo de } \\
\text { refrigerantes e fast-food versus a mesma mídia } \\
\text { querendo crianças saudáveis. }\end{array}$ & $\begin{array}{l}\text { A influência da mídia no consumo de } \\
\text { refrigerantes e fast-food versus a mesma } \\
\text { mídia querendo crianças saudáveis: uma } \\
\text { proposta para a educação infantil. }\end{array}$ \\
\hline 4. Deméter & Transgênicos: os dois lados da moeda. & $\begin{array}{l}\text { Os dois lados da moeda sobre os alimentos } \\
\text { transgênicos: uma proposta para a educação } \\
\text { de jovens e adultos. }\end{array}$ \\
\hline 5. Hera & $\begin{array}{l}\text { Clareamento dentário: seus benefícios, riscos e } \\
\text { as informações que precisamos saber antes de } \\
\text { realizar o procedimento. }\end{array}$ & $\begin{array}{l}\text { O clareamento dentário, procedimento caseiro } \\
\text { e clínico: uma sequência didática para a } \\
\text { educação de jovens e adultos. }\end{array}$ \\
\hline 6. Hígia & $\begin{array}{l}\text { O uso indiscriminado da Ritalina no meio } \\
\text { escolar. }\end{array}$ & $\begin{array}{l}\text { O uso indiscriminado da ritalina no meio } \\
\text { escolar. }\end{array}$ \\
\hline 7. Íris & $\begin{array}{l}\text { Seu tema era a Ritalina, mas não formulou } \\
\text { a questão sociocientífica, pois não concluiu } \\
\text { "TCC I". }\end{array}$ & - \\
\hline 8. Nêmesis & $\begin{array}{l}\text { Disposição inadequada dos lixos: para onde } \\
\text { vão os medicamentos? }\end{array}$ & $\begin{array}{l}\text { O meio ambiente pede socorro com o descarte } \\
\text { inadequado de medicamentos: uma proposta } \\
\text { para a educação de jovens e adultos. }\end{array}$ \\
\hline 9. Nice & $\begin{array}{l}\text { Seu tema era relacionado ao descarte de } \\
\text { pilhas e baterias, mas não formulou a questão } \\
\text { sociocientífica, pois não concluiu "TCC II". }\end{array}$ & e \\
\hline
\end{tabular}


Quadro 3 - continuação

\begin{tabular}{|l|l|l|}
\hline Estudante & \multicolumn{1}{|c|}{ Questão sociocientífica } & \multicolumn{1}{|c|}{ Título do TCC } \\
\hline 10. Tálassa & $\begin{array}{l}\text { Seu tema em "TCC I" era relacionado aos } \\
\text { alimentos industrializados no lanche escolar, } \\
\text { e, em "TCC II", era a Ritalina. Não formulou } \\
\text { a questão sociocientífica, porque trancou a } \\
\text { matrícula de "TCC II" na segunda semana de } \\
\text { aula. }\end{array}$ & - \\
\hline 11. Tália & $\begin{array}{l}\text { Com a alta do petróleo, o carro elétrico seria o } \\
\text { meio mais econômico de locomoção? }\end{array}$ & $\begin{array}{l}\text { Carro elétrico, inovação tecnológica e } \\
\text { sustentabilidade: uma proposta para a } \\
\text { educação de jovens e adultos. }\end{array}$ \\
\hline
\end{tabular}

*Optamos por não registrar as referências dos TCC para preservar a identidade das estudantes.

Fonte: elaborado pelos autores.

Explicamos às alunas que a questão sociocientífica não precisaria ser formulada necessariamente na forma de uma pergunta, mas que deveria ser apresentada como um dilema, uma controvérsia. Acreditamos que as questões elaboradas por Afrodite, Artêmis, Atena, Deméter, Nêmesis e Tália foram as que corresponderam ao que se é esperado na perspectiva da Educação por meio das questões sociocientíficas. Hera e Hígia foram as que tiveram mais dificuldade em elaborar suas questões sociocientíficas ou que se dedicaram menos, pois não se trata de uma tarefa simples, já que a questão sociocientífica tem que ser construída; ela não se apresenta pronta.

É possível notar que as estudantes escolheram temas presentes na indústria cultural. A despersonalização física dos indivíduos foi representada pelos temas que discutem sobre os dentes excessivamente brancos e os padrões de cabelos para mulheres. O comportamento padronizado foi simbolizado com o tema sobre a Ritalina. Já a sociedade do descarte foi representada pelo tema dos medicamentos, e a primazia da técnica, dominando seres humanos e natureza, foi exemplificada pelos alimentos geneticamente modificados.

Por sua vez, a soberania do capital, direcionando o que fazemos e consumimos, foi representada pelo tema do carro elétrico, que não é, ainda, significativamente utilizado no Brasil, principalmente por causa da indústria do petróleo. Por fim, o ciclo de consumo foi discutido no tema sobre a influência da mídia na alimentação altamente calórica, ao mesmo tempo em que privilegia indivíduos saudáveis e esbeltos. A intenção das estudantes era a de fazer um trabalho crítico sobre os temas controversos que decidiram estudar.

\section{Considerações finais}

No desenvolvimento da disciplina "TCC", quando este estudo foi realizado com onze estudantes do curso de Pedagogia, identificamos algumas características semiformativas e outras formativas de acordo com o referencial adorniano. Nesse sentido, percebemos que, entre a semiformação e a formação, parece haver um caminho de transição. Esse caminho não está delimitado. Ele precisa ser construído coletiva e teoricamente. Um curso ou uma disciplina é 
apenas o ponto de partida para que o docente promova sua própria subjetividade, autonomia e criatividade, tanto na sala de aula como na pesquisa, pois a indústria cultural a serviço da ideologia burguesa continuará a combater o "sujeito pensante" (ADORNO; HORKHEIMER, 1985), representado principalmente pelo professor.

O fato de apenas Atena ter escolhido primeiro o nível de ensino e depois o tema sociocientífico pode indicar que essa graduanda, por ser professora auxiliar numa escola pública municipal, tenha tido alguma oportunidade de desenvolver um trabalho com maior autonomia. Apesar de ser auxiliar, Atena participava do planejamento coletivo de projetos e atividades e mencionou algumas vezes que era importante observar o interesse das crianças. Atena já havia estudado a proposta de ensino do município e estava convicta, desde as primeiras aulas, de que faria seu trabalho na Educação Infantil. As oportunidades de estudo e trabalho que Atena vivenciava possivelmente contribuíram para a construção de sua confiança na elaboração de uma questão sociocientífica voltada para crianças.

Ao elaborarem as questões sociocientíficas para professores, como no caso da Ritalina ou para a EJA, as estudantes não agiram contra os propósitos da instituição, pois a formação do pedagogo abrange a atuação desse profissional na Educação Infantil e nos anos iniciais do Ensino Fundamental, atuando na formação de crianças, adolescentes, jovens e adultos, além da possibilidade de atuação como gestores. Entretanto, ao deixar as alunas livres para escolherem o nível de ensino, elas tiveram dificuldade em elaborar uma questão sociocientífica para crianças e optaram pelo caminho mais fácil e rápido. O fato de não termos encontrado, em 2015, nenhum artigo sobre questões sociocientíficas ou temas controversos na Educação Infantil ou nos anos iniciais pode ter aumentado ainda mais a insegurança para se realizar essa tarefa, inclusive a insegurança da própria professora orientadora.

Acreditamos que esta pesquisa possa auxiliar professores e pesquisadores que desejam trabalhar com questões sociocientíficas nos cursos de Pedagogia, pois, para as participantes deste estudo, essa perspectiva de ensino de Ciências proporcionou a ampliação da compreensão dos temas controversos que mais as incomodavam, bem como as auxiliou a perceber a complexidade que envolve os temas que decidiram estudar.

A Educação na perspectiva das questões sociocientíficas contribuiu para uma formação crítica em Ciências da Natureza a pedagogas em formação, tanto para atuarem na docência, como no processo formativo da elaboração do TCC. A construção da autonomia, da criatividade e da valorização da subjetividade na busca pela autoria no trabalho acadêmico foi um processo árduo, com inseguranças, dificuldades e resistências, mostrando que o caminho para a formação é repleto de obstáculos, mas que podem ser superados pelo processo contínuo de estudo e reflexão.

\section{Referências}

ADORNO, W. T. Educação e emancipação. Rio de Janeiro: Paz \& Terra, 1995a.

ADORNO, W. T. Notas marginais sobre teoria e práxis. In: ADORNO, T. Palavras e sinais: modelos críticos 2. Petrópolis: Vozes, 1995b. p. 202-229. 
Genovese, C. L. C. R.; Carvalho, W. L. P.; Genovese, L. G. R.

ADORNO, W. T. Tabus que pairam sobre a profissão de ensinar. In: ADORNO, T. Palavras e sinais: modelos críticos 2. Petrópolis: Vozes, 1995c. p. 83-103.

ADORNO, W. T. Teoria da semicultura. Educação \& Sociedade, Campinas, ano 17, n. 56, p. 388-411, 1996.

ADORNO, T. W.; HORKHEIMER, M. Dialética do esclarecimento: fragmentos filosóficos. Rio de Janeiro: Zahar, 1985.

BOGDAN, R. C.; BIKLEN, S. K. Investigação qualitativa em educação: uma introdução à teoria e aos métodos. Porto: Porto Editora, 2010.

BORTOLETTO, A.; CARVALHO, L. P. Uma proposta de formação continuada de professores de ciências e matemática na interface do agir comunicativo e das questões sociocientíficas. Amazônia, Belém, v. 9, n. 17, p. 141-160, 2012. DOI: http://dx.doi. org/10.18542/amazrecm.v9i17.1659.

BRASIL. Lei $n^{\circ} 5.692$, de 11 de agosto de 1971. Fixa diretrizes e bases para o ensino de $1^{\circ}$ e $2^{\circ}$ graus, e dá outras providências. Diário Oficial da União: seção 1, Brasília, p. 6377, 12 ago. 1971. Disponível em: http://www2.camara.leg.br/legin/fed/lei/1970-1979/lei-5692-11agosto-1971-357752-norma-pl.html. Acesso em: 8 jul. 2016.

BRASIL. Ministério da Educação. A área de ciências da natureza e suas tecnologias. In: BRASIL. Ministério da Educação. Base nacional comum curricular: educação é a base. Brasília: ME, 2017. p. 321-341. Disponível em: http://basenacionalcomum.mec.gov.br/ images/BNCC_EI_EF_110518_versaofinal_site.pdf. Acesso em: 9 out. 2019.

CONTRERAS, J. A autonomia de professores. São Paulo: Cortez, 2002.

FEITOSA, D. Estudantes devem tomar cuidado com o estresse no TCC. Católica Digital: agência experimental de notícias. Goiânia, 23 maio 2017. Disponível em: http:/ /www.ucg.br/ ucg/agencia/home/secao.asp?id_secao=1346. Acesso em: 23 maio 2017

FRACALANZA, H.; AMARAL, I. A.; GOUVEIA, M. S. F. O ensino de ciências no primeiro grau. São Paulo: Atual, 1986.

GALVÃO, C.; REIS, P.; FREIRE, S. A discussão de controvérsias sociocientíficas na formação de professores. Ciência \& Educação, Bauru, v. 17, n. 3, p. 505-522, 2011. DOI: https://doi.org/10.1590/S1516-73132011000300001.

GIROUX, H. A. Professores como intelectuais transformadores. In: GIROUX, H. A. Os professores como intelectuais: rumo a uma pedagogia crítica da aprendizagem. Porto Alegre: Artes Médicas, 1997. p. 157-164.

GUIMARÃES, M. A. Raciocínio informal e a discussão de questões sociocientíficas: o exemplo das células-tronco humanas. 2011. 218 f. Tese (Doutorado em Educação para a Ciência) - Faculdade de Ciências, Universidade Estadual Paulista, Bauru, 2011.

HORKHEIMER, M. Teoria tradicional e teoria crítica. In: HORKHEIMER, M.; ADORNO, T. Textos escolhidos. São Paulo: Abril Cultural, 1983. p. 31-68.

MAAR, W. L. Adorno, semiformação e educação. Educação \& Sociedade, Campinas, v. 24, n. 83, p. 459-476, 2003. DOI: https://doi.org/10.1590/S0101-73302003000200008. 
MARCONDES, M. E. R.; CARMO, M. P.; SUART, R. C.; SILVA, E. L.; SOUZA, F. L.; SANTOS JR., J. B.; AKAHOSHI, L. H. Materiais instrucionais numa perspectiva CTSA: uma análise de unidades didáticas produzidas por professores de química em formação continuada. Investigações em Ensino de Ciências, Porto Alegre, v. 14, n. 2, p. 281-298, 2009.

MARTÍNEZ PÉREZ, L. F. Questões sociocientíficas na prática docente: ideologia, autonomia e formação de professores. São Paulo: Ed. Unesp, 2012. Disponível em: http:// books.scielo.org/id/bd67t/pdf/martinez-9788539303540.pdf. Acesso em: 10 abr. 2017.

MARTÍNEZ PÉREZ, L. F.; CARVALHO, W. L. P. Contribuições e dificuldades da abordagem de questões sociocientíficas na prática de professores de ciências. Educação e Pesquisa, São Paulo, v. 38, n. 3, p. 727-741, 2012. DOI: https://doi.org/10.1590/S151797022012005000014.

RATCLIFFE, M.; GRACE, M. Science education for citizenship: teaching socioscientific issues. Maidenhead: Open University Press, 2003.

REIS, P. Controvérsias sócio-científicas: discutir ou não discutir? percursos de aprendizagem na disciplina de ciências da terra e da vida. 2004. Tese (Doutorado) Faculdade de Ciências, Universidade de Lisboa, Lisboa, 2004.

REIS, P.; GALVÃO, C. Os professores de ciências naturais e a discussão de controvérsias sociocientíficas: dois casos distintos. Revista Electrónica de Enseñanza de la Ciencias, Vigo, v. 7, n. 3, p. 746-772, 2008.

SADLER, T. D. Informal reasoning regarding socioscientific issues: a critical review of research. Journal of Research in Science Teaching, Hoboken, v. 41, n. 5, p. 513-536, 2004. DOI: https://doi.org/10.1002/tea.20009.

SANTOS, W. L. P.; MORTIMER, E. F. Abordagem de aspectos sociocientíficos em aulas de ciências: possibilidades e limitações. Investigações em Ensino de Ciências, Porto Alegre, v. 14, n. 2, p. 191-218, 2009.

SASSERON, L. H.; CARVALHO, A. M. P. Almejando a alfabetização científica no ensino fundamental: a proposição e a procura de indicadores do processo. Investigações em Ensino de Ciências, Porto Alegre, v. 13, n. 3, p.333-352, 2008.

SCHÖN, D. A. Educando o profissional reflexivo: um novo design para o ensino e a aprendizagem. Porto Alegre: Artmed, 2000.

VISSICARO, S. P.; FIGUEIRÔA, S. F. M.; ARAÚJO, M. S. Questões sociocientíficas nos anos iniciais do ensino fundamental: o tema água em evidência. Indagatio Didactica, Aveiro, v. 8, n. 1, p. 1596-1609, 2016.

ZIMAN, J. Enseñanza y aprendizaje sobre la ciencia y la sociedad. México: Fondo de Cultura Económica, 1985.

Recebido em: 02/02/2019. Aceito em: 09/06/2019

Contato: UFG, Faculdade de Educação, Rua 235, Setor Universitário, Goiânia, CEP: 74. 605-050, GO, Brasil. 
